\title{
TU/e emonownen

\section{A low complexity VBLAST OFDM detection algorithm for wireless LAN systems}

\section{Citation for published version (APA):}

Wu, Y., Lei, Z., \& Sun, S. (2004). A low complexity VBLAST OFDM detection algorithm for wireless LAN systems. IEEE Communications Letters, 8(6), 374-376. https://doi.org/10.1109/LCOMM.2004.828187

DOI:

10.1109/LCOMM.2004.828187

Document status and date:

Published: 01/01/2004

\section{Document Version:}

Publisher's PDF, also known as Version of Record (includes final page, issue and volume numbers)

\section{Please check the document version of this publication:}

- A submitted manuscript is the version of the article upon submission and before peer-review. There can be important differences between the submitted version and the official published version of record. People interested in the research are advised to contact the author for the final version of the publication, or visit the $\mathrm{DOI}$ to the publisher's website.

- The final author version and the galley proof are versions of the publication after peer review.

- The final published version features the final layout of the paper including the volume, issue and page numbers.

Link to publication

\section{General rights}

Copyright and moral rights for the publications made accessible in the public portal are retained by the authors and/or other copyright owners and it is a condition of accessing publications that users recognise and abide by the legal requirements associated with these rights.

- Users may download and print one copy of any publication from the public portal for the purpose of private study or research.

- You may not further distribute the material or use it for any profit-making activity or commercial gain

- You may freely distribute the URL identifying the publication in the public portal.

If the publication is distributed under the terms of Article 25fa of the Dutch Copyright Act, indicated by the "Taverne" license above, please follow below link for the End User Agreement:

www.tue.nl/taverne

Take down policy

If you believe that this document breaches copyright please contact us at:

openaccess@tue.nl

providing details and we will investigate your claim. 


\title{
A Low Complexity VBLAST OFDM Detection Algorithm for Wireless LAN Systems
}

\author{
Wu Yan, Sumei Sun, and Zhongding Lei, Senior Member, IEEE
}

\begin{abstract}
A low complexity detection algorithm for VBLAST OFDM system is presented. Using the fact that the correlation among neighboring subcarriers is high for wireless LAN channels, this algorithm significantly reduces the complexity of VBLAST OFDM detection. The performance degradation of the proposed algorithm is small compared to conventional detection.
\end{abstract}

Index Terms-Detection, MIMD, OFDM, Vertical Bell Lab's layered space time (VBLAST).

\section{INTRODUCTION}

V BLAST (Vertical Bell Lab's layered Space Time) architecture [1] can be combined with OFDM to achieve high data rate transmission in frequency selective fading channels. The VBLAST OFDM system with $N$ transmit antennas, $M$ receive antennas, and $K$ subcarriers can be formulated as

$$
\mathcal{R}=\left[\begin{array}{cccc}
\mathbf{H}_{1,1} & \mathbf{H}_{1,2} & \cdots & \mathbf{H}_{1, N} \\
\mathbf{H}_{2,1} & \mathbf{H}_{2,2} & \cdots & \mathbf{H}_{2, N} \\
\vdots & \vdots & \ddots & \vdots \\
\mathbf{H}_{M, 1} & \mathbf{H}_{M, 2} & \cdots & \mathbf{H}_{M, N}
\end{array}\right]\left[\begin{array}{c}
\mathbf{X}_{1} \\
\mathbf{X}_{2} \\
\vdots \\
\mathbf{X}_{N}
\end{array}\right]+\left[\begin{array}{c}
\mathbf{N}_{1} \\
\mathbf{N}_{2} \\
\vdots \\
\mathbf{N}_{M}
\end{array}\right]
$$

where $\mathbf{H}_{i, j}$ is a $K \times K$ diagonal matrix corresponding to the single input single output frequency response of all the subcarriers between transmit antenna $j$ and receive antenna $i . \mathbf{X}_{j}$ is the frequency-domain OFDM symbol transmitted at antenna $j$ and $\mathbf{N}_{i}$ is the additive white aussian noise (AWGN) noise vector at receive antenna $i$. Examining (1), we can see that on each subcarrier we have effectively an $M \times N$ narrow band VBLAST system. Therefore, detection of VBLAST OFDM system can be carried out using standard VBLAST detection algorithm on each subcarrier individually.

The conventional VBLAST detection employs an ordered serial zero-forcing nulling plus cancellation technique. The optimal detection order is determined to maximize the minimum post-detection signal-to-noise ratio (SNR) of all data streams. This algorithm is computation intensive as a number of pseudo inverse operations need to be performed. The most numerically stable way to compute the pseudo inverse is to use the singular value decomposition (SVD). An alternative way is to use the QR decomposition, which involves less computation. However, it is less numerically stable since one is required to invert the

\footnotetext{
Manuscript received November 2, 2003. The associate editor coordinating the review of this letter and approving it for publication was Dr. S. K. Wilson.

The authors are with the Institute for Infocomm Research, Singapore 119613 (e-mail:wuyan@i2r.a-star.edu.sg).

Digital Object Identifier 10.1109/LCOMM.2004.828187
}

upper triangular $R$ of the $\mathrm{QR}$ factorization to obtain the pseudo inverse. Therefore, in this letter we adopt the SVD approach for all pseudo-inverse calculations.

To reduce the complexity of VBLAST detection, a QR decomposition technique was proposed in [2] ${ }^{1}$, and it achieves the same performance as conventional VBLAST detection so long as the optimal detection order is known. However, determining the optimal detection order for VBLAST OFDM systems requires taking pseudo-inverse $N$ times on each subcarrier, which incurs large computation load. Another QR related square-root detection algorithm was introduced in [3] for minimum mean square error (MMSE) nulling technique. As the MMSE technique requires extra complexity to estimate the variance of the noise, we therefore, focus our study in this letter on the zero-forcing approach.

In this letter, we propose a new low complexity detection algorithm for VBLAST OFDM system, making use of the correlation between different subcarriers. In this algorithm, the subcarriers are partitioned into a number of groups such that the correlation among subcarriers within each group is above a threshold value referred as threshold correlation (TC). For each group, conventional VBLAST detection is first performed on the center subcarrier and the detection order is recorded. Following the recorded order, the other subcarriers in the same group are detected using QR decomposition technique as in [2]. We show that this algorithm reduces the complexity of VBLAST OFDM detection significantly. Moreover, the performance degradation of the proposed algorithm is small.

\section{LOW COMPLEXITY VBLAST OFDM DETECTION ALGORITHM}

For VBLAST OFDM system, the channels between different transmit and receive antennas are statistically the same ${ }^{2}$. Therefore, we only need to study one channel and the same properties apply to all the other channels. The impulse response of the multipath channel can be written as $\mathbf{h}=\left[h_{1}, h_{2}, \ldots, h_{L+1}\right]^{T}$, where $L$ is the channel order. The frequency response of the channel for a $K$ subcarrier OFDM system is given by

$$
\mathbf{h}_{\mathcal{F}}=\mathbf{F h}
$$

where the $(i, j)$ th element of $\mathbf{F}, F_{i, j}=(1 / \sqrt{K}) \exp (-j 2 \pi$ $\times(((i-1)(j-1)) / K)), i=1,2, \ldots, K, j=1,2, \ldots, L+1$.

${ }^{1}$ To avoid confusion, we emphasis that the QR-based technique in [2] is different from conventional detection with calculating pseudo inverse using $\mathrm{QR}$ decomposition.

${ }^{2}$ In this letter, we assume the channels between different transmit and receive antennas are spatially uncorrelated. 


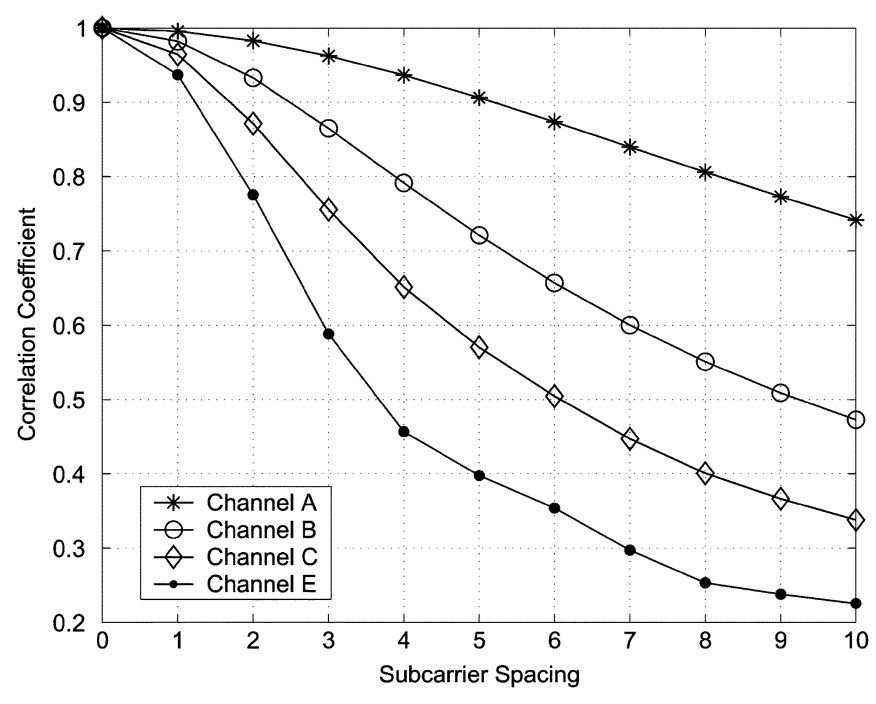

Fig. 1. Correlation coefficient among neighboring subcarriers for HiperLAN/2 channels.

The correlation coefficient of subcarriers $m$ and $n$ can be written as

$$
\rho_{m, n}=\frac{\mathbf{f}_{m}^{H} \mathrm{E}\left(\mathbf{h} \mathbf{h}^{H}\right) \mathbf{f}_{n}}{\sqrt{\mathbf{f}_{m}^{H} \mathrm{E}\left(\mathbf{h} \mathbf{h}^{H}\right) \mathbf{f}_{m} \mathbf{f}_{n}^{H} \mathrm{E}\left(\mathbf{h} \mathbf{h}^{H}\right) \mathbf{f}_{n}}}
$$

where $\mathbf{f}_{m}$ denotes the $m$ th column of $\mathbf{F}$ and $\mathrm{E}(x)$ denotes statistical expectation and superscript ${ }^{H}$ denotes Hermitian. Due to the symmetrical properties of the DFT matrix, the correlation coefficient $\rho_{m, n}$ depends only on the absolute values of $m-n$.

Fig. 1 shows the correlation coefficients among neighboring subcarriers for non-line-of-sight (NLOS) HiperLAN/2 channel models A, B, C, and E given in [4]. The power delay profiles of the channels are exponential, with root mean square (rms) delay spread ranging from 50 (channel A) to $250 \mathrm{~ns}$ (channel E). The maximum delay spread for all the channels is $800 \mathrm{~ns}$, which corresponds to 16 channel taps for a $20-\mathrm{MHz}$ bandwidth sample spaced channel. Here, We use a 64-subcarrier OFDM system with 16-tap cyclic prefix. From Fig. 1, we can see that the correlation is high among neighboring subcarriers for all the channels. This implies that the channel changes only slightly within a number of subcarriers. Hence, it is reasonable to assume the optimal detection order does not change within a group of subcarriers, among which the correlation is above TC. Once TC is set, from Fig. 1, we can determine the size of the group, in which the same detection order is used. Denoting the group size as $k$, we propose the following low complexity detection algorithms for VBLAST OFDM system:

1) Pre-determine the value of $\mathrm{TC}$, and hence the group size $k$ for the channel of interest, based on the statistical knowledge of the channel correlation;

2) Partition the subcarriers into groups of size $k$;

3) Perform conventional VBLAST detection on the center subcarrier within a group and record the optimal detection order $\mathbf{p}$;
4) Perform detection on subcarriers in the same group using $Q R$ decomposition technique according to detection order p;

5) Repeat steps 3-4 until all the groups are detected.

Since QR decomposition technique requires much less complexity compared to conventional VBLAST detection [2], large reduction in complexity can be achieved using the proposed algorithm.

The optimal detection order might change within the group, which causes degradation in performance of the proposed algorithm. Hence, there is a tradeoff on the choice of TC. The larger the value of TC, the less probable that the optimal detection order will change within the group and hence less performance degradation. However, larger TC results in smaller group size $k$, thus, less reduction in complexity. We will study the BER performance for different TC values in Section IV.

\section{COMPUTATION COMPLEXITY COMPARISON}

In this section, we compare the amount of arithmetic operations needed to determine the nulling vectors and detection order for the conventional detection and the proposed low complexity algorithm for an $M \times N$ VBLAST OFDM system. We list the complexity reduction in different complex arithmetic operations. The reduction in total amount of floating point operations (flops) is also given. As we are dealing with complex numbers here, addition is counted as 2 flops, multiplication and division are counted as 6 flops each and square root is counted as 10 flops. We also show some numerical results on the reduction in complexity for two specific VBLAST OFDM systems with $4 \times 4$ and $6 \times 4$ antenna configurations. We use Modified Gram-Schmidt method [5] to compute QR decomposition. We adopt SUD-based approach to compute the pseudo inverse of channel matrix $\mathbf{H}$ on each subcarrier.

We denote the total operation counts for conventional VBLAST detection on one subcarrier as $\mathcal{N}$. We also define the operation counts by using QR decomposition technique on one subcarrier as $\mathcal{Q}$. The total number of operations required for conventional VBLAST OFDM detection for a group of $k$ subcarriers is equal to $k \times \mathcal{N}$. By using the low complexity algorithm we proposed, the total number of operation counts is equal to $\mathcal{N}+(k-1) \times \mathcal{Q}$. Based on this calculation, we listed, in Table I, the complexity reduction using the proposed method compared to conventional VBLAST OFDM detection to determine all the nulling vectors and detection orders for a group of $k$ subcarriers. We use channel $\mathrm{A}$ as an example. Setting TC $=0.9$ results in group size of $k=6$ and TC $=0.8$ results in $k=9$.

From Table I, we can see that the complexity can be reduced by about $80 \%$ for all the cases for channel $\mathrm{A}$. The reduction becomes smaller for less correlated channels. However, according to our calculation, even for the least correlated channel $\mathrm{E}$ with $\mathrm{TC}=0.9$, we can still achieve complexity reduction of $47.10 \%$ for $4 \times 4$ systems and $46.59 \%$ for $6 \times 4$ systems.

Recently, a number of MIMO channel models were proposed in IEEE 802.11n documents [6]. The correlation in frequency 
TABLE I

Complexity Reduction Using the Proposed Algorithm Compared to Conventional VBLAST OFDM Detection (ChanNel A)

\begin{tabular}{|c|c|c|c|c|c|c|}
\hline & \multirow[b]{2}{*}{$\mathcal{N}$} & \multirow[b]{2}{*}{$\mathcal{Q}$} & \multicolumn{2}{|c|}{$\mathrm{TC}=0.9$} & \multicolumn{2}{|c|}{$\mathrm{TC}=0.8$} \\
\hline & & & $4 \times 4$ & $6 \times 4$ & $4 \times 4$ & $6 \times 4$ \\
\hline mul & $\begin{array}{c}5 M N^{3}+2 M^{2} N^{2}+\frac{14}{3} N^{4}+23 N^{3} \\
+4 M N^{2}-\frac{44}{3} N^{2}-4 M N-21 N\end{array}$ & $M N$ & $82.10 \%$ & $81.93 \%$ & $87.57 \%$ & $87.39 \%$ \\
\hline add & $\begin{array}{c}3 M N^{3}+2 M^{2} N^{2}+\frac{8}{3} N^{4}+5 N^{3} \\
-4 M N^{2}-\frac{8}{3} N^{2}-7 N\end{array}$ & $M N^{2}-\frac{1}{2} N^{2}-\frac{1}{2} N$ & $81.03 \%$ & $80.82 \%$ & $86.43 \%$ & $86.20 \%$ \\
\hline $\operatorname{div}$ & $M N^{2}+4 N^{3}+3 N^{2}-7 N$ & $M N$ & $79.41 \%$ & $77.96 \%$ & $84.71 \%$ & $83.15 \%$ \\
\hline sqrt & $8 N^{3}-4 N^{2}-4 N$ & $N$ & $82.56 \%$ & $82.56 \%$ & $88.07 \%$ & $88.07 \%$ \\
\hline total & $\begin{array}{c}36 M N^{3}+16 M^{2} N^{3}+\frac{100}{3} N^{4}+252 N^{3} \\
+22 M N^{2}-\frac{346}{3} N^{2}-24 M N-222 N\end{array}$ & $\begin{array}{c}8 M N^{2}-N^{2}+6 M N \\
+9 N\end{array}$ & $81.89 \%$ & $81.66 \%$ & $87.34 \%$ & $87.10 \%$ \\
\hline
\end{tabular}

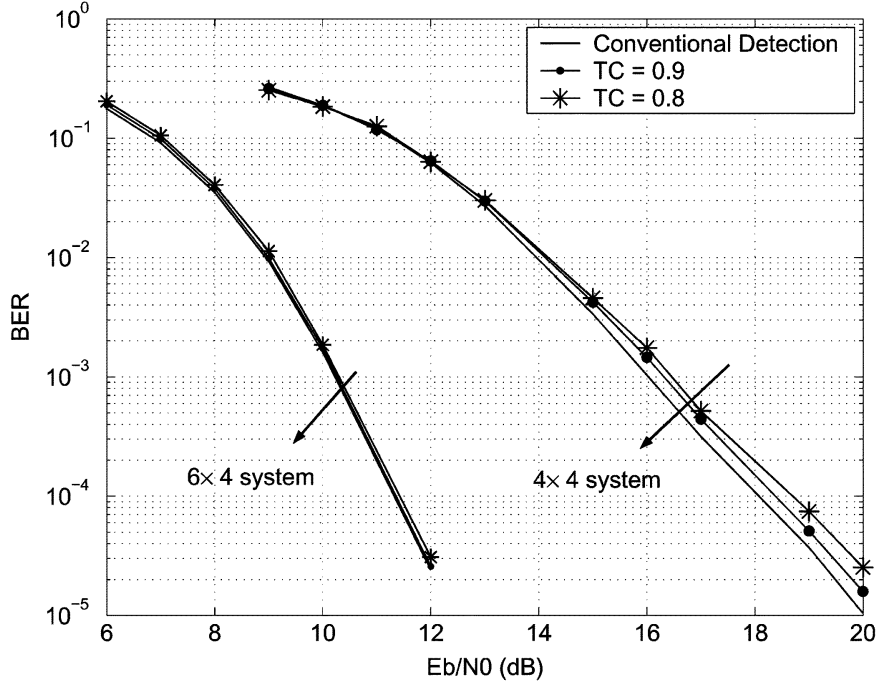

Fig. 2. BER comparison of conventional VBLAST OFDM detection and the proposed low complexity algorithm. (QPSK modulation, 1/2 convolutional code.

for the proposed MIMO channels is higher compared to the channel A to $\mathrm{E}$ we studied above, due to smaller rms delay spread. Therefore, for those channel, the proposed detection scheme is able to achieve larger reduction in complexity. The IEEE 802.11n channels also incorporate spatial correlation between antennas. However, the correlation in frequency for each antenna pair is similar to the spatially uncorrelated channel models. Therefore, the proposed algorithm, which utilizes the correlation in frequency, can be applied for spatially correlated channels with minor modifications.

\section{Simulation Results}

Simulations are carried out to study the BER of the proposed algorithm. The transmit power is evenly distributed on each transmit antenna with total power equal to 1 . We assume the channels between different antennas are uncorrelated. To estimate the channel, we send $N$ orthogonal preambles from $N$ transmit antennas before the transmission of real data. The channels are estimated using the least squares criterion. The error control coding used in the simulation is a half-rate convolutional code with constraint length of 7 and generator polynomials $g_{0}=133_{8}$ and $g_{1}=171_{8}$. As in [1], coding is applied to each MIMO transmit branch independently. Interleaver design follows IEEE 802.11a standard. We use hard decision Viterbi algorithm to decode the received data. From the simulations using different channel models, we observed the performance degradation depends only on the value of TC, not on the channel models used. Therefore, we use channel A in all the simulations in this letter.

Fig. 2 shows the BER performance of the conventional VBLAST OFDM detection and the proposed algorithm for a $4 \times 4$ and a $6 \times 4$ system, respectively. For both cases, the degradation in BER using the proposed method is only marginal compared to the conventional method. At the same time, significant reduction in computation complexity can be achieved as we have shown in the previous section.

In practice, it is not necessary to obtain the explicit values of the correlation at the receiver. We can always use a pessimistic estimate of the group size, i.e., smaller group size, for the chosen TC. Although smaller group size results in less reduction in complexity, it guarantees good performance of the system.

\section{CONCLUSION}

We present a low complexity VBLAST OFDM detection algorithm, which determines a common detection order for a group of subcarriers by employing conventional VBLAST detection on the center subcarrier in the group. The detection on the other subcarriers is carried out using QR decomposition technique. This algorithm significantly reduces the complexity of the VBLAST OFDM detection with only marginal degradation to the system performance.

\section{REFERENCES}

[1] G. J. Foschini, G. D. Golden, R. A. Valenzuela, and P. W. Wolnianski, "Simplified processing for high spectral efficiency wireless communication employing multi-element arrays," IEEE J. Select. Areas Commun., vol. 17, pp. 1841-1852, Nov. 1999.

[2] W. K. Wai, C.-Y. Tsui, and R. S. Cheng, "A low complexity architecture of the V-BLAST system," in Proc. IEEE Wireless Communications and Networking Conf., vol. 1, 2000, pp. 310-314.

[3] B. Hassibi, "An efficient square-root algorithm for BLAST," in Proc. IEEE Int. Conf. on Acoustics, Speech, and Signal Processing, vol. 2, June 2000, pp. 737-740.

[4] J. Medbo, H. Hallenberg, and J.-E. Berg, "Propagation characteristics at $5 \mathrm{GHz}$ in typical radio-LAN scenarios," in Proc. IEEE Vehicular Technology Conf., vol. 1, May 1999, pp. 185-189.

[5] G. H. Golub and C. F. Van Loan, Matrix Computations, 3rd ed. Baltimore, MD: John Hopkins Univ. Press, 1996.

[6] V. Erceg et al., "Indoor MIMO WLAN Channel Models,", IEEE 802.11 Work Group Document, No. IEEE 802.11-03/161r1, July 2003. 